\title{
Attitudes of Biology Students Toward Ethical Issues Concerning the Beginning and The End of Human Life in Albania
}

\author{
Odeta Vava (Laknori) \\ department of Biology, Faculty of Natural Sciences, Tirana University, Tirana, Albania
}

\begin{abstract}
This paper aims to explore the attitude towards ethical issues regarding the beginning and the end of human life among biology students. The study has two phases: during first phase 118 participants had to fill a questionnaire regarding their cultural value, religious beliefs and their attitude towards situations about abortion and euthanasia. Statistics show different level of knowledge about abortion and euthanasia among biology students. $1 \%$ of the students don't have any kind of information about abortion, 51\% are somehow informed and $48 \%$ are well informed. The situation regarding euthanasia is different. $43,22 \%$ of the students don't even know what euthanasia means, $48,31 \%$ have some information about the practice of intentionally ending life to relieve pain and only $8,47 \%$ are well informed. The results show a significant lack of information about euthanasia. All the situations where students justify abortion are predicted by the law. So, even when students face situations regarding selective abortion, they are against it. Regarding euthanasia, the situation is different. They appear more openminded but at the same time they show a strong connection with the family and traditional value (even when the patient is adult and responsible, students don't justify euthanasia without family consent). Second phase of the study includes the students attending bioethical course during their studies for master degree in education. They present their attitude toward abortion and euthanasia through different cases they choose themselves. Even in this phase, students are against selective abortion. As for euthanasia, students weight quality versus quantity of life.
\end{abstract}

Keywords: abortion, euthanasia, quality of life 


\section{LCNAEDULATION}

02-04 JULY, 2021

Oxford, United Kingdom

\section{Introduction}

Almost every time we hear the phrase bioethical issues, we associate it with medical practice. Ethical dilemmas regarding the beginning and the end of human life, are for sure a hot topic in this group. Different studies done in different parts of the world (Fillus IC., 2019; Hariharan S., 2006; Kolodziejczyk I., 2020; Ranasinghe AWIP., 2020) evaluate knowledge and attitude toward abortion and euthanasia among health care students. This is fair enough considering the fact that those students are the ones that while practicing their professions, will face dilemmas such as: what is more important, to fulfill their task to save lives at any cost, or to respectlconsider a patient's wish even when this means going against life. According to this logic, it makes sense that the health care students are prepared to face such dilemmas, while attending bioethical course during their studies. But there are two parties facing ethical issues about the beginning and the end of life: "the patient" and the health care worker. As the second party is prepared, we cannot say the same thing about the first one. This is exactly where the idea of my study emerged. Do biology students have knowledges about abortion? What about euthanasia? Which are some of the factors that one can considerate before making decisions about termination of pregnancies, or the end of life?

Abortion in Albania was legalized on December 7, 1995. Before that year, Albania had a policy against abortion excluding the cases of rape and incest, or if the patient was under the age of 16. The major factor associated with people's attitude toward the ethical issues concerning the beginning and the end of human life is cultural value. The publication of Institute of Statistics about abortion in Albania during 2020 states that one of the main reasons for inducing abortion is the sex of the fetus doesn't match the "expectations" of the father. Unfortunately, the existing law that regulates different situations where it is possible to terminate pregnancy nearby health care facilities doesn't comment on selective abortion, neither based on gender, nor on the number of fetuses. Another factor that influence the decision about abortion or euthanasia is the religious belief. It is necessary to emphasize that Albanians were prohibited by the regime to practice, or to share openly their religious beliefs from 1945 up to 1992. In this scenario one important reason for not inducing abortion or euthanasia is "out of the list". So, one can expect a rise in the number of abortions or common practice of euthanasia, but the regime made sure that would not happen by making abortion and euthanasia illegal. Although euthanasia is still not legal in Albania, relatives or family members tend to euthanize terminal ill patients (Bocari G., 2010) through applying tranquilizers in an abusive dosage, or refusing to keep on consistently applying life prolonging treatment.

What is happening now that many factors that can influence the decision of taking abortion, or applying euthanasia, came to life? Is it easier or harder for the younger generation to face dilemmas about the beginning and the end of life? Does the new generation fully acknowledge the ethical issue about abortion? And what if they have to face everyday a more suffering parent, family member? 


\section{Methods}

In attempt to answer the questions above I chose two methods. First, I conducted a survey among biology students in Tirana University. Each student had to answer at 13 questions related to their cultural value (where are they from, the education level of their parents), their religious beliefs and how much do they practice them. They had to define their level of knowledge about abortion and euthanasia, the sources of information they were able to use to gain such knowledge. During the last part of the survey students had to list factors that may influence their decision about taking an abortion or not. Also, they were presented with different situations where they had to decide whether to justify abortion and euthanasia, or not.

The second phase of the study was conducted among the presumptive teachers of biology in the middle high schools in Albania. The students attending bioethical course during their studies for master degree in education were told to present any situation they choose to explain their attitude toward abortion or euthanasia.

\section{Results and discussion}

This study was conducted in Tirana university in Albania. 118 students participated at the first phase. Table 1 outlines several features of the sample.

Table 1 Several features of the sample for phase one

\begin{tabular}{|l|l|l|}
\hline Demographic features & Frequency (\%) \\
\hline Gender identification & Male & $9(7,63)$ \\
\cline { 2 - 3 } & Female & $107(90,68)$ \\
\cline { 2 - 3 } & Male transgender & \\
\cline { 2 - 3 } & Female transgender & \\
\cline { 2 - 3 } & Bisexual & $2(1,69)$ \\
\hline Parent's level of education & University & $57(48,31)$ \\
\cline { 2 - 3 } & Middle high school & $61(51,69)$ \\
\hline Year of study & I & $21(17,8)$ \\
\cline { 2 - 3 } & II & $76(64,4)$ \\
\cline { 2 - 3 } & III & $21(17,8)$ \\
\hline & Muslim & $94(79,88)$ \\
\hline & Catholic & $4(3,39)$ \\
\hline & Orthodox & $2(9,31)$ \\
\hline \multirow{5}{*}{ Religiosity } & Protestant & $7(5,83)$ \\
\hline & Other & $5(4,24)$ \\
\hline & Non-believer & $75(63,56)$ \\
\cline { 2 - 3 } & $\begin{array}{l}\text { Believer but don't } \\
\text { practice }\end{array}$ & $38(32,2)$ \\
\cline { 2 - 3 } & Practice & \\
\hline
\end{tabular}


Biology students that participated at first phase of the study haven't studied bioethics. So, although students progress in their years of study, they are not equipped with bioethical tools to use in ethical issues concerning abortion and euthanasia.

Filling the questionnaire, biology students had to define their level of knowledge about abortion, euthanasia and the sources of information they were able to use to gain such knowledge. As it is shown in table 2 the participants have information about abortion, but they show a lack of knowledge about euthanasia.

Table 2 Participants' level of knowledge about abortion and euthanasia

\begin{tabular}{|l|l|l|l|}
\hline \multirow{2}{*}{ Topic } & \multicolumn{3}{|l|}{ Level of knowledge } \\
\cline { 2 - 4 } & $\begin{array}{l}\text { Not informed at all } \\
\text { (frequency in } \\
\text { percentage) }\end{array}$ & $\begin{array}{l}\text { Somehow informed } \\
\text { (frequency in } \\
\text { percentage) }\end{array}$ & $\begin{array}{l}\text { Well informed } \\
\text { (frequency in } \\
\text { percentage) }\end{array}$ \\
\hline Abortion & $1(1 \%)$ & $61(51 \%)$ & $56(48 \%)$ \\
\hline Euthanasia & $51(43,22)$ & $57(48,31)$ & $10(8,47 \%)$ \\
\hline
\end{tabular}

Figure 1 enlists sources of knowledge that participants used to gain information about ethical issues concerning the beginning and the end of life. Biology students used as information even the school textbooks, although they don't attend bioethical course. One of the sources that is majorly used is social media. Maybe in the future we may need to discuss the influence of social media in bioethical issues.

Figure 1: Sources of knowledge about ethical issues

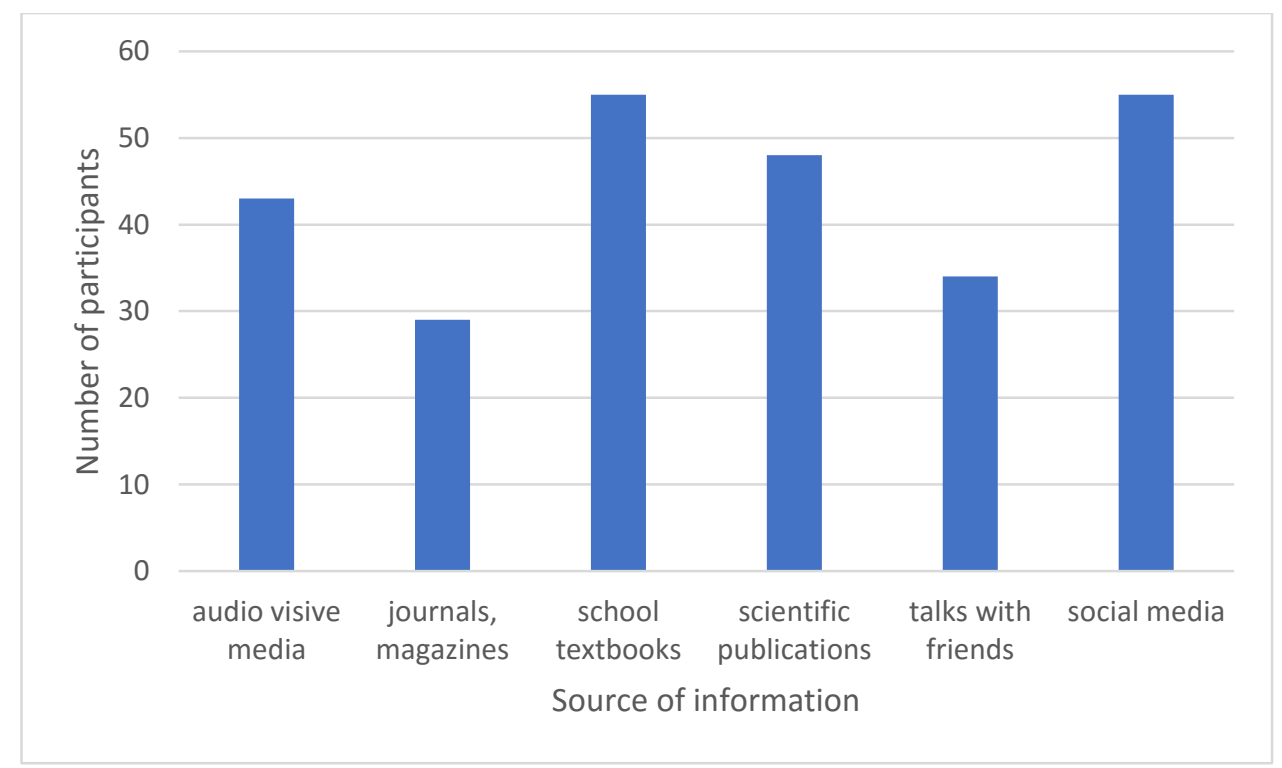

The second phase of the study was conducted among students attending bioethical course during their studies for master degree in education. They presented different cases of abortion 


\section{SICNAẼULCATION}

02-04 JULY, 2021

Oxford, United Kingdom

or euthanasia and argued their attitude toward bioethical issues. Differently from participants of phase one, students of phase two have developed moral reasoning and this is reflected even in their arguments. As for abortion, I can say that participants' approach toward the termination of pregnancy support women's rights to decide for themselves. It doesn't matter that in many cases abortion causes social problems for the pregnant female. This fact can be seen as positive. Finally, Albanian women feel empowered to make decisions for themselves.

Another interesting fact that emerged by the interviews is that the debate about abortion or euthanasia is displayed from what the family and society think, to what is more important: the quality or the quantity of life.

But I must emphasize that the connection with the family is very strong among students. This fact appears while discussing passive euthanasia cases. They all find it difficult to terminate the life of a suffering and terminal ill patient without the permission of the family.

In none of the cases they argued against abortion or euthanasia for religious beliefs.

\section{Conclusion}

This paper presents how biology students approach to the ethical issues about the beginning and the end of human life. Results obtained in both phases of the study show a non-tolerance attitude of the students toward selective abortion. Students that participated during phase one show a lack of information about euthanasia. This is due to the fact that euthanasia is illegal in Albania (although that the actual laws that regulate euthanasia approach in Albania creates the gaps where it is possible to decide if to perform euthanasia or not). 


\section{References}

Bocari G., Shaqiri E. and Vyshka G., (December 2010): The actuality and historical background of covert Euthanasia in Albania, J. Med Ethics, 36(12): 842-844

Fillus IC. and Rodrigues CFA., (2019): Knowledge of medical ethics and bioethics by medical students. Rev Bioética;27(3):482-489. doi:10.1590/ 1983-80422019273332

Hariharan S., Jonnalagadda R., Walrond E. and Moseley H., (2006): Knowledge, attitudes and practice of healthcare ethics and law among doctors and nurses in Barbados. BMC Med Ethics 7(1):1-9. doi:10.1186/ 1472-6939-7-72.

INSTAT (2020): Men and women in Albania 2019

Kolodziejczyk I. and Kuzma J., (2020): Knowledge and Attitudes Towards Abortion and Euthanasia Among Health Students in Papua New Guinea. Dove Press journal: Advances in Medical Education and Practice, 11:977-987.

Ranasinghe AWIP., Fernando B., Sumathipala A., and Gunathunga W, (2020): Medical ethics: knowledge, attitude and practice among doctors in three teaching hospitals in Sri Lanka. BMC Med Ethics; 69. doi:10.1186/s12910-020-00511-43 